\title{
Safety and efficacy of sunitinib in patients from Latin America: subanalysis of an expanded access trial in metastatic renal cell carcinoma
}

This article was published in the following Dove Press journal:

OncoTargets and Therapy

23 September 2016

Number of times this article has been viewed

\author{
Carlos H Barrios' \\ Daniel Herchenhorn² \\ Matías Chacón ${ }^{3}$ \\ Paula Cabrera-Galeana ${ }^{4}$ \\ Peter Sajben ${ }^{5}$ \\ Ke Zhang ${ }^{6}$ \\ 'Department of Medicine, PUCRS \\ School of Medicine, Porto Alegre, \\ ${ }^{2}$ Division of Clinical Oncology, \\ Instituto Nacional do Câncer, Rio \\ de Janeiro, Brazil; ${ }^{3}$ Clinical Oncology, \\ Alexander Fleming Institute, Buenos \\ Aires, Argentina; ${ }^{4}$ Department of \\ Medical Oncology, Instituto Nacional \\ de Cancerología, México, Centro \\ Oncológico Issemym Edomex, México; \\ ${ }^{5}$ Pfizer Oncology, New York, NY, \\ ${ }^{6}$ Pfizer Oncology, La Jolla, CA, USA
}

Correspondence: Carlos H Barrios PUCRS School of Medicine, Padre Chagas 66, conj 203, Porto Alegre RS 90570 080, Brazil

Tel +55 5I 32227852

Fax +55 5I 33462217

Email chbe@via-rs.net
Background: Sunitinib is an approved treatment for metastatic renal cell carcinoma (mRCC). The safety profile and efficacy of sunitinib were confirmed in a global expanded access trial (ClinicalTrials.gov identifier: NCT00130897). This report presents a subanalysis of the final trial data from patients in Latin America.

Methods: Treatment-naïve or previously treated $\mathrm{mRCC}$ patients aged $\geq 18$ years received oral sunitinib at a starting dose of $50 \mathrm{mg} /$ day on a 4 -weeks-on/2-weeks-off schedule. Treatment continued until disease progression, unacceptable toxicity, or withdrawal of consent. Safety was assessed regularly, and tumor measurements were scheduled per local practice (using Response Evaluation Criteria in Solid Tumors).

Results: In total, 348 patients from Latin America received sunitinib. Overall, $75 \%$ of patients had two or more sites of metastatic disease, $28 \%$ were aged $\geq 65$ years, $14 \%$ had an Eastern Cooperative Oncology Group performance status $\geq 2,9 \%$ had brain metastases, $9 \%$ had no prior nephrectomy, and 5\% had non-clear cell RCC. Median treatment duration was 8 months, and median follow-up was 15.1 months. In total, 326 patients (94\%) discontinued treatment, primarily due to death (41\%) or lack of efficacy (22\%). Most treatment-related adverse events were of mild to moderate severity (grade 1/2). Mucosal inflammation (reported in $54 \%$ of patients), diarrhea (53\%), and asthenia (41\%) were the most common any-grade treatmentrelated adverse events. Asthenia (12\%), neutropenia (10\%), and fatigue and thrombocytopenia (both $9 \%$ ) were the most common grade $3 / 4$ treatment-related adverse events. In total, 311 patients were included for tumor response, of whom eight (3\%) had a complete response and $46(15 \%)$ a partial response, yielding an objective response rate of $17 \%$. Median duration of response, progression-free survival, and overall survival were $26.7,12.1$, and 16.9 months, respectively.

Conclusion: The efficacy and safety profile of sunitinib in patients with mRCC from Latin America was comparable to that in the entire cohort of the global expanded access trial.

Keywords: sunitinib, kidney cancer, expanded-access trial, Latin America, tyrosine kinase inhibitor

\section{Introduction}

Kidney cancer is the twelfth most common cancer worldwide, with an estimated 338,000 new diagnoses and 143,000 deaths in 2012. ${ }^{1,2}$ Most patients ( $~ 85 \%$ ) diagnosed with kidney cancer have renal cell carcinoma (RCC) and approximately one-third will present with metastatic disease. ${ }^{3}$ Metastatic RCC (mRCC) is known to have a poor prognosis such that before the advent of targeted therapy that dramatically altered the therapeutic landscape, 5-year survival rates were $<10 \%{ }^{4}$ 
Sunitinib malate is an oral, multitargeted inhibitor of vascular endothelial growth factor receptors, plateletderived growth factor receptors, and other receptor tyrosine kinases, ${ }^{5-7}$ approved worldwide for mRCC treatment. Prior to regulatory approval, a global expanded access trial of $>4,500$ patients confirmed the safety profile and efficacy of sunitinib in a broad population of patients who were ineligible for, or had no access to, other sunitinib trials. ${ }^{8}$

A recent article by Goss et $\mathrm{al}^{9}$ highlighted that few clinical cancer trials are carried out in Latin America and that publication of epidemiological and trial data from the region is infrequent. Using the final trial data set, we report the safety and efficacy of sunitinib in $\mathrm{mRCC}$ patients in Latin American countries enrolled in the global expanded access trial; this is the first report from this region.

\section{Patients and methods Study population}

Patients $\geq 18$ years of age with histologically confirmed mRCC who were either treatment-naïve or previously treated and were ineligible to participate in the ongoing sunitinib clinical trials, but had investigator-determined potential to derive clinical benefit from sunitinib, were included in the study. Other inclusion criteria were resolution of acute toxicity arising from prior systemic therapy; radiotherapy or surgical procedure for $\mathrm{mRCC}$ to National Cancer Institute Common Terminology Criteria for Adverse Events (NCI CTCAE) version 3.0 grade 1 or less; and adequate organ function. Exclusion criteria included prior treatment with sunitinib and diagnosis with any acute medical or psychiatric condition that, in the investigator's judgment, would make inclusion inappropriate. More details on inclusion/exclusion criteria have been previously published. ${ }^{8}$

\section{Study design and treatment}

This was a subanalysis of data from mRCC patients in Latin America (Argentina, Brazil, Chile, Colombia, Ecuador, Mexico, Panama, Peru, and Venezuela) enrolled in an international open-label, expanded access trial of sunitinib (SUTENT ${ }^{\circledR}$; Pfizer Inc., New York, NY, USA) (ClinicalTrials. gov identifier: NCT00130897). The study was conducted in compliance with the Declaration of Helsinki and the International Conference on Harmonization Good Clinical Practice guidelines and was approved by the ethics committee at each center (Table S1). All patients provided written, informed consent. The primary objective was to provide access to sunitinib for patients who were ineligible for participation in, or had no access to, sunitinib clinical trials (in countries where regulatory approval had not yet been granted), but who had the potential to derive benefit, as judged by the investigator. Secondary objectives included assessment of safety and efficacy (objective response rate [ORR], progression-free survival [PFS], and overall survival [OS]).

Patients were enrolled between June 2005 and December 2007. Accrual of new patients was discontinued on a countryby-country basis according to treatment availability. All patients received oral sunitinib at a starting dose of $50 \mathrm{mg} /$ day on a 4-weeks-on/2-weeks-off schedule, in repeated 6-week cycles. Dose reductions to $37.5,25$, and then to $12.5 \mathrm{mg} /$ day were permitted based on individual tolerance. In May 2006, a protocol amendment was implemented that gave the option of administering sunitinib on a continuous daily dosing schedule (usual starting dose $37.5 \mathrm{mg} /$ day). Treatment continued until disease progression, unacceptable toxicity, or withdrawal of consent.

\section{Study assessments}

Evaluations performed at screening included assessment of disease and medical history, physical examination, biochemistry and hematology tests, and recording of concomitant medications. Safety data collection was mandatory and performed on days 1, 14, and 28 of the first cycle and on days 1 and 28 of subsequent cycles, until a protocol amendment (May 2006) removed the day 28 assessment in cycles $\geq 3$. Safety assessments included physical examination, Eastern Cooperative Oncology Group performance status (ECOG PS), biochemistry and hematology tests, and 12-lead electrocardiogram. Adverse events (AEs) were graded according to NCI CTCAE version 3.0.

Tumor assessments were guided by the Response Evaluation Criteria in Solid Tumors (RECIST, version 1.0), ${ }^{10}$ but were not scheduled in the study protocol, and were performed according to the local standard of care, with response, PFS, and OS data collected when possible. ORR was defined as the proportion of patients with a complete or partial response according to RECIST. ${ }^{10}$ PFS was defined as the time from the start of treatment to disease progression or death due to any cause, whichever event occurred first. Only deaths that occurred within 28 days of the last dose were counted as PFS events; however, disease progression was not restricted to the treatment period plus the 28-day follow-up period. OS was defined as the time from start of therapy to death from any cause. Data on survival events were collected up to July 15, 2008. For patients who were not known to be dead at the time of analysis or the cut-off date, survival times were censored at the last follow-up. 


\section{Statistical analysis}

As this was an expanded access trial, sample size was not predetermined; no inferential analyses were planned nor any hypotheses tested. All patients who received at least one dose of sunitinib comprised the intent-to-treat population for analyses. ORR was calculated with a corresponding $95 \%$ two-sided confidence interval (CI) using standard methods based on binomial distribution. Estimates of median PFS and OS with respective $95 \%$ CIs were determined using the Kaplan-Meier method.

\section{Results}

\section{Patients}

In total, 349 patients were enrolled in Latin America, of whom 348 received at least one dose of sunitinib and comprised the intent-to-treat population for analysis. Baseline characteristics are reported in Table 1.

\section{Drug exposure}

Details of sunitinib exposure and patient disposition are reported in Table 2. The median treatment duration was 8.0 months and median follow-up was 15.1 months. A total of 326 patients (94\%) discontinued treatment, and dose reductions occurred in 168 patients (48\%).

\section{Safety}

Most treatment-related AEs were of mild to moderate severity (grade $1 / 2$; Table 3 ). Mucosal inflammation (54\% of patients), diarrhea (53\%), and asthenia ( $41 \%$ ) were the most common any-grade treatment-related, nonhematologic AEs. The most frequently reported nonhematologic grade $3 / 4$ AEs were asthenia (12\%), fatigue (9\%), diarrhea (8\%), and hand-foot syndrome (7\%). Rates of treatment-related cardiac failure or congestive cardiac failure of any grade were low $(<1 \%)$. Neutropenia, thrombocytopenia, and anemia were the most common treatment-related hematologic AEs of any grade $(28 \%, 26 \%$, and $24 \%$, respectively) and of grade $3 / 4$ $(10 \%, 9 \%$, and $8 \%$, respectively) (Table 3 ).

\section{Efficacy}

In total, 311 patients were included for tumor response (Table 4). Patients with non-RECIST tumor assessments were excluded from the analysis. Overall, ORR was $17 \%$, and clinical benefit was reported in 57\%. Median duration of response was 26.7 months (95\% CI: 19.2-53.6) and median time to tumor progression was 15.7 months (95\% CI: 13.0-18.1). ORR in patients with and without prior cytokine treatment was $19 \%$ and $15 \%$, respectively, and
Table I Baseline patient characteristics

\begin{tabular}{ll}
\hline Characteristic & All patients $\mathbf{( N = 3 4 8 )}$ \\
\cline { 2 - 2 } & $\mathbf{n}(\%)$ \\
\hline Median age (range), years & $59(19-85)$ \\
Age $\geq 65$ years & $97(28)$ \\
Male/female & $247 / 10$ I (7I/29) \\
ECOG PS & \\
0 & $160(46)$ \\
I & $139(40)$ \\
2 & $39(11)$ \\
3 & $8(2)$ \\
4 & 0 \\
Unknown & $2(<1)$ \\
Histology & \\
Clear cell & $329(95)$ \\
Non-clear cell & $19(5)$ \\
Prior nephrectomy & $311(89)$ \\
Most common metastatic sites & \\
Lung & $265(76)$ \\
Bone & $134(39)$ \\
Lymph nodes & $124(36)$ \\
Liver & $88(25)$ \\
Brain & $30(9)$ \\
Prior systemic therapy & \\
Anti-angiogenic & \\
Cytokine & $5(1)$ \\
Modified risk groups based on published & $208(60)$ \\
MSKCC data, & \\
Favorable & \\
Intermediate & $125(36)$ \\
Poor & $23(7)$ \\
\hline
\end{tabular}

Notes: ${ }^{\text {anumber }}(\%)$ of patients with missing data: prior nephrectomy $=7(2 \%)$ MSKCC risk group $=53(15 \%)$. bIncluded sorafenib and bevacizumab. cModified MSKCC risk group factors were ECOG PS $\geq 2$, low hemoglobin, and high serum calcium. ${ }^{16,17}$ Patients without prior cytokine treatment also had lactate dehydrogenase and time to interferon- $\alpha$ use of $\left\langle 1\right.$ year as risk factors. ${ }^{17}$ Patients without prior cytokine treatment were assigned to favorable, intermediate, or poorrisk groups if 0,1 or 2 , or $>2$ risk factors were present, respectively. Patients with prior cytokine therapy were assigned to favorable, intermediate, or poor-risk groups if $0, \mathrm{I}$, or $>$ I risk factors were observed, respectively. ${ }^{16}$

Abbreviations: ECOG PS, Eastern Cooperative Oncology Group performance status; MSKCC, Memorial Sloan Kettering Cancer Center.

that in subpopulations with poor prognostic features ranged from $7 \%$ to $17 \%$.

Overall, median PFS was 12.1 months (95\% CI: 10.6-14.0) (Figure 1), and median OS was 16.9 months (95\% CI: 15.1-20.2) (Figure 2). Median PFS was 12.1 months (95\% CI: 9.5-14.1) and 12.1 months (95\% CI: 9.7-16.1) in patients with and without prior cytokine treatment, respectively. Median OS was 16.6 months (95\% CI: 14.7-19.5) and 19.3 months (95\% CI: 13.8-28.5) in patients with and without prior cytokine treatment, respectively.

\section{Discussion}

This subanalysis confirms the safety profile and efficacy of sunitinib in mRCC patients enrolled in Latin America as part 
Table 2 Sunitinib exposure and patient disposition

\begin{tabular}{ll}
\hline $\begin{array}{l}\text { Population and treatment } \\
\text { parameters }\end{array}$ & All patients $\mathbf{( N = 3 4 8 )}$ \\
\cline { 2 - 2 } $\begin{array}{l}\text { Median number of treatment } \\
\text { cycles started (range) }\end{array}$ & $6(\mathrm{I}-47)$ \\
$\begin{array}{l}\text { Median duration of treatment } \\
(95 \% \mathrm{Cl}), \text { months }\end{array}$ & $8.0(6.4-9.4)$ \\
Median duration of follow-up & \\
(range), months & $\mathrm{I} 5 . \mathrm{I}(<\mathrm{I}-66)$ \\
Patients who discontinued & \\
Primary reason for discontinuation & $326(94)$ \\
Death & \\
Lack of efficacy & $14 \mathrm{I}(4 \mathrm{I})$ \\
Adverse event & $75(22)$ \\
Consent withdrawn & $46(13)$ \\
Lost to follow-up & $18(5)$ \\
Decision of sponsor & $12(3)$ \\
Protocol violation & $7(2)$ \\
Other & $2(<\mathrm{I})$ \\
Patients with dose reductions & $25(7)$ \\
Level of dose reduction & $168(48)$ \\
37.5 mg &
\end{tabular}

Abbreviation: $\mathrm{Cl}$, confidence interval.

of the global expanded access trial. Furthermore, the overall safety and efficacy profile was similar to that in the overall cohort, ${ }^{11}$ although some differences were noted.

A majority of the treatment-related AEs were mild to moderate (grade 1/2). The levels of common AEs such as mucosal inflammation (54\%) and asthenia (41\%) observed in this subanalysis were higher than those reported in the entire cohort (29\% and 22\%, respectively). ${ }^{11}$ Similarly, these AEs were more frequent in Spanish patients $(48 \%$ and $68 \%$, respectively), ${ }^{12}$ whereas Italian patients reported an elevated level of asthenia (44\%) but not mucosal inflammation (29\%). ${ }^{13}$ The incidence of mucosal inflammation in patients from the US $(29 \%)^{14}$ was similar to that reported for the entire cohort. The incidence of common grade $3 / 4$ AEs, namely asthenia (12\%), neutropenia (10\%), thrombocytopenia and fatigue (both $9 \%$ ), and diarrhea and anemia (both $8 \%$ ), were similar to that in the entire cohort, as well as the Spanish, Italian, and US subpopulations. ${ }^{11-14}$ Treatment discontinuation in the Latin American group was similar to that in the entire cohort (94\% and $95 \%$, respectively). ${ }^{11}$ Although the main reasons for discontinuation were the same, the numbers differed; $37 \%$ because of lack of efficacy and $21 \%$ because of death in the entire cohort ${ }^{11}$ compared with $22 \%$ and $41 \%$, respectively, in the Latin American population. This reversal was also noted
Table 3 Treatment-related AEs of interest and those that occurred in $\geq 10 \%$ of the intent-to-treat population $(\mathrm{N}=348)$

\begin{tabular}{|c|c|c|c|}
\hline \multirow[t]{2}{*}{ Adverse event } & \multicolumn{3}{|c|}{ n (\%) } \\
\hline & Grade I/2 & Grade 3/4 & Total $^{a}$ \\
\hline \multicolumn{4}{|l|}{ Nonhematologic AEs } \\
\hline Mucosal inflammation & $167(48)$ & $22(6)$ & $189(54)$ \\
\hline Diarrhea & $159(46)$ & $27(8)$ & $186(53)$ \\
\hline Asthenia & $99(28)$ & $42(12)$ & $|4|(4 \mid)$ \\
\hline Decreased appetite & $105(30)$ & $9(3)$ & $115(33)^{\mathrm{b}}$ \\
\hline Nausea & $106(3 \mathrm{I})$ & $7(2)$ & II $3(33)$ \\
\hline Fatigue & $74(2 I)$ & $31(9)$ & $105(30)$ \\
\hline Vomiting & $90(26)$ & $15(4)$ & $105(30)$ \\
\hline Hypertension & $70(20)$ & $21(6)$ & $91(26)$ \\
\hline Hand-foot syndrome & $63(18)$ & $23(7)$ & $87(25)^{b}$ \\
\hline Yellow skin & $83(24)$ & $\mathrm{I}(<\mathrm{I})$ & $84(24)$ \\
\hline Skin discoloration & $72(2 I)$ & 0 & $72(2 I)$ \\
\hline Headache & $62(18)$ & $5(1)$ & $67(19)$ \\
\hline Stomatitis & $61(18)$ & $5(I)$ & $66(19)$ \\
\hline Dysguesia & $63(18)$ & $2(<1)$ & $65(19)$ \\
\hline Dyspepsia & $57(16)$ & $I(<I)$ & $58(17)$ \\
\hline Abdominal pain, upper & $48(14)$ & $I(<I)$ & $49(14)$ \\
\hline Hypothyroidism & $45(13)$ & $2(<1)$ & $47(14)$ \\
\hline Epistaxis & $40(12)$ & $5(1)$ & $45(13)$ \\
\hline Abdominal pain & $36(10)$ & $5(1)$ & $4 I(12)$ \\
\hline Rash & $4 I(12)$ & 0 & $4 \mid(12)$ \\
\hline Peripheral edema & $37(1 \mathrm{I})$ & $2(<1)$ & $39(\mathrm{II})$ \\
\hline Pain in extremity & $37(11)$ & $2(<1)$ & $39(\mathrm{II})$ \\
\hline Constipation & $36(10)$ & $I(<I)$ & $37(\mathrm{II})$ \\
\hline Skin exfoliation & $35(10)$ & $I(<I)$ & $36(10)$ \\
\hline Hair color changes & $35(10)$ & 0 & $35(10)$ \\
\hline Cardiac failure & 0 & $\mathrm{I}(<\mathrm{I})$ & $\mathrm{I}(<\mathrm{I})$ \\
\hline Congestive cardiac failure & 0 & $2(<1)$ & $2(<1)$ \\
\hline \multicolumn{4}{|l|}{ Hematologic AEs } \\
\hline Neutropenia & $62(18)$ & $36(10)$ & $98(28)$ \\
\hline Thrombocytopenia & $58(17)$ & $32(9)^{c}$ & $91(26)$ \\
\hline Anemia & $57(16)$ & $26(8)$ & $83(24)$ \\
\hline Leukopenia & $44(13)$ & $10(3)$ & $54(16)$ \\
\hline
\end{tabular}

Notes: aln total, twelve patients had grade 5 treatment-related AEs (two patients each with hemorrhagic gastritis and multiple organ failure, and one patient each with thrombocytopenia, adrenal insufficiency, gastrointestinal hemorrhage, death, pneumonia, necrotizing fasciitis, septic shock, perinephric abscess, cerebrovascular accident, ischemic stroke, pulmonary hemorrhage, and hemorrhage). 'brade missing for one additional patient. 'Grade 5 thrombocytopenia occurred in one additional patient.

Abbreviation: $\mathrm{AE}$, adverse event.

in the Spanish population ( $15 \%$ and $43 \%$, respectively) ${ }^{12}$ but not in the Italian ( $46 \%$ and $17 \%$, respectively $)^{13}$ or US patients (32\% and $19 \%$, respectively). ${ }^{14}$ Whether these data reflect underlying ethnic differences, natural variation, or geographic-based differences in assessment and management remains to be determined.

The ORR in the Latin American population (17\%) was similar to that seen in the overall cohort $(16 \%) .{ }^{11}$ Of note, the ORR in patients with prior cytokine therapy was similar to that in patients with no prior cytokine therapy 
Table 4 RECIST-defined tumor response and clinical benefit

\begin{tabular}{|c|c|c|c|c|c|c|c|}
\hline \multirow[t]{3}{*}{ Parameters } & \multirow{2}{*}{$\begin{array}{l}\text { All patients }^{\mathrm{a}} \\
(\mathrm{N}=3 \mathrm{II})\end{array}$} & \multicolumn{2}{|c|}{ Prior cytokines } & \multicolumn{4}{|c|}{ Patient subgroups } \\
\hline & & $\begin{array}{l}\text { Yes } \\
(n=188)\end{array}$ & $\begin{array}{l}\text { No } \\
(n=123)\end{array}$ & $\begin{array}{l}\text { Age } \geq 65 \text { years } \\
(n=84)\end{array}$ & $\begin{array}{l}\text { ECOG PS } \geq 2 \\
(n=42)\end{array}$ & $\begin{array}{l}\text { Non-clear } \\
\text { cell histology } \\
(\mathrm{n}=18)\end{array}$ & $\begin{array}{l}\text { Brain } \\
\text { metastases } \\
(n=29)\end{array}$ \\
\hline & \multicolumn{7}{|c|}{ n (\%) } \\
\hline Number of evaluable patients & $226(73)$ & $140(74)$ & $86(70)$ & $5 I(6 I)$ & $20(48)$ & $14(78)$ & $16(55)$ \\
\hline Objective response & $54(17)$ & $35(19)$ & $19(15)$ & $14(17)$ & $4(9)$ & $3(17)$ & $2(7)$ \\
\hline Complete response & $8(3)$ & $3(2)$ & $5(4)$ & $I(I)$ & 0 & $I(6)$ & I (3) \\
\hline Partial response & $46(15)$ & $32(17)$ & $14(11)$ & $13(15)$ & $4(9)$ & $2(I I)$ & I (3) \\
\hline Stable disease $\geq 3$ months & $124(40)$ & $71(38)$ & $53(43)$ & $27(32)$ & $6(14)$ & $7(39)$ & $9(31)$ \\
\hline $\begin{array}{l}\text { Progressive disease or stable } \\
\text { disease }<3 \text { months }\end{array}$ & $48(15)$ & $34(18)$ & $14(11)$ & $10(12)$ & $10(24)$ & $4(22)$ & $5(17)$ \\
\hline Clinical benefit ${ }^{\mathrm{b}}$ & I 78 (57) & $106(56)$ & $72(59)$ & $41(49)$ & $10(24)$ & $10(56)$ & II (38) \\
\hline
\end{tabular}

Notes: aPatients were excluded from the intent-to-treat population for objective response if they had non-RECIST tumor assessments. A further 85 patients were included in the analysis but were not assessed $(n=38)$, not evaluable $(n=1)$, or had missing data $(n=46)$. bClinical benefit $=$ complete response + partial response + stable disease for $\geq 3$ months.

Abbreviations: ECOG PS, Eastern Cooperative Oncology Group performance status; RECIST, Response Evaluation Criteria in Solid Tumors.

(19\% versus $15 \%$ ), suggesting a benefit even in patients previously treated with cytokines. Patients $>65$ years of age also achieved a similar ORR (17\%) and had a clinical benefit rate of $49 \%$. Latin America, like the rest of the world, is facing an aging population ${ }^{9}$ and the finding that older patients may also respond to sunitinib is worth noting. Interestingly, ORR was also similar in patients with nonclear cell RCC (17\%), as was clinical benefit rate $(56 \%)$. In addition, clinical benefit was observed in patients with other poor prognostic features, such as ECOG PS $\geq 2(24 \%)$ and brain metastases (38\%).

Median PFS was slightly longer in the Latin American patients than in the overall cohort (12.1 and 9.4 months, respectively), but median OS was slightly shorter (16.9 and 18.7 months, respectively). ${ }^{11}$ This could potentially be explained by the limited treatment options available in the

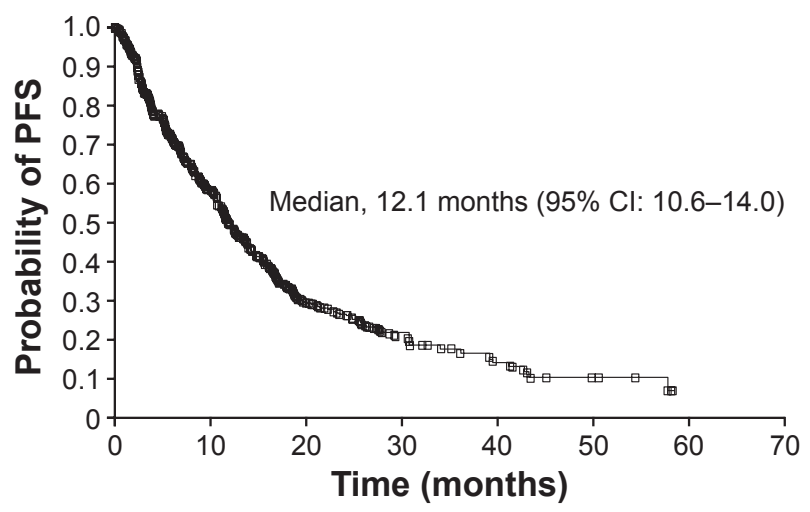

Figure I Kaplan-Meier estimate of PFS.

Note: Patients were excluded from the intent-to-treat population for Kaplan-Meier estimate of PFS if they had non-RECIST tumor assessments.

Abbreviations: $\mathrm{Cl}$, confidence interval; PFS, progression-free survival; RECIST, Response Evaluation Criteria in Solid Tumors. region after progression. The Latin American subgroup may have had a somewhat better prognosis than the overall cohort, having fewer patients classified as poor risk (7\%) than in the overall cohort $(26 \%) .{ }^{11}$ The subanalyses of patients from Spain, Italy, and the US revealed median PFS and OS values ranging from 9.1 to 9.7 months and from 15.1 to 27.2 months, respectively. ${ }^{12-14}$ Overall, the Latin American patients had the longest PFS of the subpopulations analyzed.

Participation of Latin America in cancer clinical trials has been increasing in the past decade, but still remains low in comparison with that of North America or Europe. ${ }^{15}$ At the time of writing, there were 335 open cancer clinical trials registered in South America, 129 in Mexico, and 112 in Central America, whereas there were 7,431 in the US, 1,103 in Canada, and 4,798 in Europe (ClinicalTrials.gov, accessed July 28, 2015). Subanalyses of large global clinical trials such as this study provide an important opportunity to evaluate the regional outcomes and better understand the

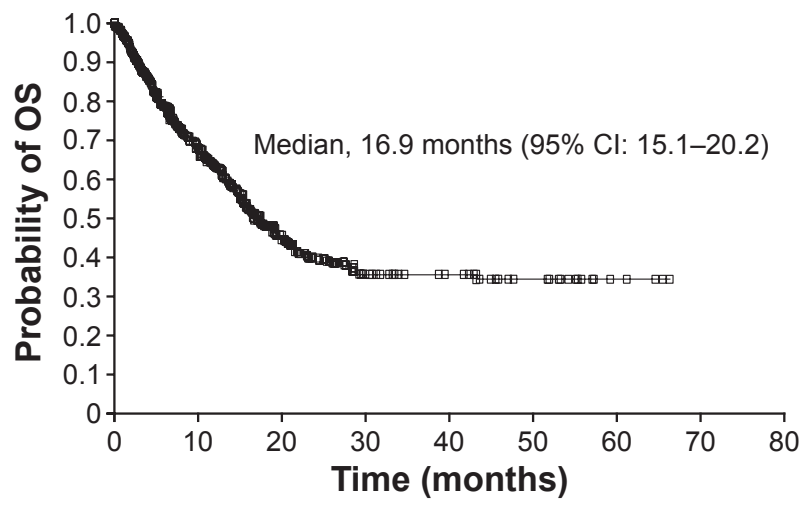

Figure 2 Kaplan-Meier estimate of OS.

Abbreviations: $\mathrm{Cl}$, confidence interval; OS, overall survival. 
potential regional specifics in areas where the available data are scant, such as Latin America.

The limitations of this expanded access study include the lack of a reference arm and an independent central review of tumor response. The tumor assessments were not mandated in the protocol and were performed according to the local standard of care, thus leading to missing data and a degree of variation in the findings.

In conclusion, these data confirm the safety and efficacy profile of sunitinib in a population of patients from Latin America with $\mathrm{mRCC}$ who encompassed a wide range of disease states, including poor prognosis of disease.

\section{Acknowledgments}

The authors would like to thank all the patients who participated in the trial and their families, as well as all trial investigators, research nurses, study coordinators, and operations staff. Medical writing support was provided by Andy Gannon and Jo Chapman at ACUMED ${ }^{\circledR}$, an Ashfield company, part of UDG Healthcare plc (New York, NY, USA), with funding from Pfizer Inc. Editorial support was provided by Jaya Vas, PhD, of Engage Scientific Solutions, and was funded by Pfizer Inc.

\section{Author contributions}

$\mathrm{CHB}, \mathrm{DH}, \mathrm{MC}$, and PC-G contributed to acquisition of data for this study. PS and KZ participated in supervision of this study. KZ contributed to the statistical analysis. All authors contributed to analysis and interpretation of the data, participated in developing the manuscript, read and approved the final draft, and take responsibility for the integrity of the data and the accuracy of the data analyses.

\section{Disclosure}

$\mathrm{CHB}$ has reported receiving consultant fees and research grants from Pfizer, Novartis, and Roche. PS and KZ are fulltime employees of Pfizer with stock ownership. DH, MC, and PC-G report no conflicts of interest in this work.

\section{References}

1. World Cancer Research Fund International. Kidney cancer statistics [Internet]. Available from: http://www.wcrf.org/cancer_statistics/data_ specific_cancers/kidney_cancer_statistics.php. Accessed July 25, 2014.
2. Ferlay J, Soerjomataram I, Dikshit R, et al. Cancer incidence and mortality worldwide: sources, methods and major patterns in GLOBOCAN 2012. Int J Cancer. 2015;136(5):E359-E386.

3. Ljungberg B. Prognostic factors in renal cell carcinoma. Scand J Surg. 2004;93(2):118-125.

4. Motzer RJ, Bander NH, Nanus DM. Renal-cell carcinoma. $N$ Engl $J$ Med. 1996;335(12):865-875.

5. Faivre S, Delbaldo C, Vera K, et al. Safety, pharmacokinetic, and antitumor activity of SU11248, a novel oral multitarget tyrosine kinase inhibitor, in patients with cancer. J Clin Oncol. 2006;24(1):25-35.

6. Abrams TJ, Lee LB, Murray LJ, Pryer NK, Cherrington JM. SU1 1248 inhibits KIT and platelet-derived growth factor receptor $\beta$ in preclinical models of human small cell lung cancer. Mol Cancer Ther. 2003;2(5): 471-478.

7. Mendel DB, Laird AD, Xin X, et al. In vivo antitumor activity of SU11248, a novel tyrosine kinase inhibitor targeting vascular endothelial growth factor and platelet-derived growth factor receptors determination of a pharmacokinetic/pharmacodynamic relationship. Clin Cancer Res. 2003;9(1):327-337.

8. Gore ME, Szczylik C, Porta C, et al. Safety and efficacy of sunitinib for metastatic renal-cell carcinoma: an expanded-access trial. Lancet Oncol. 2009;10(8):757-763.

9. Goss PE, Lee BL, Badovinac-Crnjevic T, et al. Planning cancer control in Latin America and the Caribbean. Lancet Oncol. 2013;14(5): 391-436.

10. Therasse P, Arbuck SG, Eisenhauer EA, et al. New guidelines to evaluate the response to treatment in solid tumors. European Organization for Research and Treatment of Cancer, National Cancer Institute of the United States, National Cancer Institute of Canada. J Natl Cancer Inst. 2000;92(3):205-216.

11. Gore M, Szczylik C, Porta C, et al. Final results from the large sunitinib global expanded-access trial in metastatic renal cell carcinoma. $\mathrm{Br} J$ Cancer. 2015;113(1):12-19.

12. Castellano D, Garcia del Muro X, Climent MA, et al. Sunitinib expanded-access trial in metastatic renal cell carcinoma (mRCC)-final results from Spain. Eur J Cancer. 2013;49(2):S666.

13. Sternberg CN, Calabrò F, Bracarda $\mathrm{S}$ et al. Safety and efficacy of sunitinib in patients from Italy with metastatic renal cell carcinoma: final results from an expanded-access trial. Oncology. 2015;88(5): $273-280$.

14. Hutson T, Dudek A, Fishman M, et al. Sunitinib expanded-access trial in metastatic renal cell carcinoma (mRCC)-final US results. $B J U$ International. Presented at: The 12th International Kidney Cancer Symposium; October 25-26, 2013; Chicago, IL. Available from: http:// onlinelibrary.wiley.com/enhanced/doi/10.1111/bju.12478. Accessed February 19, 2016.

15. Barrios C, Werutsky G, Martinez-Mesa J. The global conduct of cancer clinical trials: challenges and opportunities. Presented at: American Society of Clinical Oncology; May 30 to June 3, 2014; Chicago, IL. Available from: http://meetinglibrary.asco.org/content/11500132-156. Accessed February 19, 2016.

16. Motzer RJ, Bacik J, Mazumdar M. Prognostic factors for survival of patients with stage IV renal cell carcinoma: Memorial SloanKettering Cancer Center experience. Clin Cancer Res. 2004;10(18): 6302S-6303S.

17. Motzer RJ, Bacik J, Murphy BA, Russo P, Mazumdar M. Interferon-alfa as a comparative treatment for clinical trials of new therapies against advanced renal cell carcinoma. J Clin Oncol. 2002;20(1):289-296. 


\section{Supplementary material}

Table SI List of ethics committees or institutional review boards that approved this study

\begin{tabular}{|c|c|}
\hline Country & Ethics committee or institutional review board \\
\hline \multirow[t]{5}{*}{ Argentina } & Comite Independiente de Etica para Ensayos en Farmacologia Clinica Fundación de Estudios Farmacologicos \\
\hline & y de Medicamentos (FEFyM) \\
\hline & Comite de Etica de la Investigacion del CEMIC \\
\hline & Comite Docencia e Investigacion - Hospital Frances \\
\hline & Comite de Docencia e Investigacion Instituto Alexander Flemin \\
\hline \multirow[t]{9}{*}{ Brazil } & Comitê de Ética em Pesquisa da Irmandade da Santa Casa de Misericórdia de Porto Alegre \\
\hline & Comitê de Ética em Pesquisa da Pontifícia Universidade Católica do Rio Grande do Sul - PUCRS \\
\hline & Comitê de Ética em Pesquisa Fundação Antonio Prudente-Hospital A.C. Camargo-Hospital do Câncer \\
\hline & Comitê de Ética em Pesquisa do Instituto Nacional de Câncer - INCA \\
\hline & Comitê de Ética em Pesquisa do Hospital Israelita Albert Einstein \\
\hline & Comitê de Ética em Pesquisa da Sociedade Beneficente de Senhoras Hospital Sírio Libanês \\
\hline & Comitê de Ética em Pesquisa da Fundação Mário Penna \\
\hline & Comitê de Ética em Pesquisa Fundação Hospital Amaral Carvalho \\
\hline & Comitê de Ética em Pesquisa da Maternidade Climério de Oliveira - UFBA Complexo Hospitalar Universitário \\
\hline Chile & Comité de Ética de Investigación Servicio de Salud Metropolitano Norte \\
\hline \multirow[t]{3}{*}{ Colombia } & Comite Corporativo de Etica en Investigacion de la Fundacion Santa Fe de Bogota \\
\hline & Comite Corporativo de Etica en Investigacion \\
\hline & Comite de Etica e Investigacion Biomedica, Fundacion Clinica Valle de Lili Comite de Etica en Investigaciones \\
\hline \multirow[t]{4}{*}{ Ecuador } & Universidad Central del Ecuador \\
\hline & Comision Nacional de Investigacion Cientifica Instituto Mexicano del Seguro \\
\hline & Comite de Bioetica ISSSTEP \\
\hline & Hospital Christus Muguerza del Parque Comite de Etica \\
\hline \multirow[t]{4}{*}{ Mexico } & Instituto Nacional de Ciencias Medicas y Nutrición Salvador Zubiran Comite Institucional de Investigacion \\
\hline & Biomedica en Humanos \\
\hline & Hospital Regional Merida ISSSTE Comite de Investigacion y Bioetica \\
\hline & Comite Cientifico de Bioetica e Investigacion del Centro Oncologico Estatal \\
\hline Panama & Instituto Conmemorativo Gorgas \\
\hline \multirow[t]{3}{*}{ Peru } & Comite de Etica de Investigacion del HNGAI \\
\hline & Comite de Etica del Hospital Nacional Edgardo Rebagliati Martins \\
\hline & Centro Nacional de Bioética. CENABI \\
\hline Venezuela & Comisión de Ética del Hospital Oncológico Padre Machado Hospital Oncológico Padre Machado \\
\hline
\end{tabular}

\section{Publish your work in this journal}

OncoTargets and Therapy is an international, peer-reviewed, open access journal focusing on the pathological basis of all cancers, potential targets for therapy and treatment protocols employed to improve the management of cancer patients. The journal also focuses on the impact of management programs and new therapeutic agents and protocols on

\section{Dovepress}

patient perspectives such as quality of life, adherence and satisfaction. The manuscript management system is completely online and includes a very quick and fair peer-review system, which is all easy to use. Visit http://www.dovepress.com/testimonials.php to read real quotes from published authors. 